\title{
Efficacy of Transcutaneous Functional Electrical Stimulation on Urinary Incontinence in Myelomeningocele: Results of a Pilot Study
}

\author{
Abdol-Mohammad Kajbafzadeh, Lida Sharifi-Rad, SeyedSaeid Dianat \\ Pediatric Urology Research Center, Department of Pediatric Urology (AMK, SSD) and Department of \\ Physical Therapy (LSR), Children's Hospital, Tehran University of Medical Sciences, Islamic Republic \\ of Iran
}

\begin{abstract}
Purpose: To investigate the efficacy of transcutaneous functional electrical stimulation (FES) on voiding symptoms in children with myelomeningocele (MMC) suffering from neuropathic urinary incontinence.

Materials and Methods: Six girls and 6 boys with moderate to severe urinary incontinence secondary to MMC were included. Median age of children was 5.04 (range: 3-11) years. They underwent a urodynamic study (UDS) before and 3 months after FES with special attention to detrusor leak point pressure (DLPP) and maximal bladder capacity (MBC). Daily incontinence score, frequency of pad changing, and enuresis were also assessed before and three months after treatment. Fifteen courses of FES for 15 minutes 3 times per week were performed with low frequency $(40 \mathrm{~Hz})$ electrical current, duration of $250 \mu \mathrm{s}$, with hold and rest time of 2 seconds.

Results: Nine children had improvement on urinary incontinence score, while three children had no improvement. Median DLPP was significantly increased from 38.5 (range: 12-50) $\mathrm{cm} \mathrm{H}_{2} \mathrm{O}$ to 59.5 (range: 18-83) $\mathrm{cm} \mathrm{H}_{2} \mathrm{O}(\mathrm{P}=0.003$ ). MBC was significantly increased from median value of 155 (range: $60-250) \mathrm{mL}$ to 200 (range: $110-300) \mathrm{mL}(\mathrm{P}=0.007$ ).

Conclusions: This is a pilot study showing that FES therapy might have positive effects on improvement of voiding symptoms of MMC children with neurogenic urinary incontinence in terms of daily incontinence score and UDS parameters.
\end{abstract}

Key words: myelomeningocele; functional electrical stimulation; urinary incontinence

Int Braz J Urol. 2010; 36: 614-20

\section{INTRODUCTION}

Myelomeningocele (MMC) is the most common cause of neurogenic bladder in children. Bladder function in these children is affected by disordered innervation of detrusor muscle and external urethral sphincter that may lead to hydronephrosis or reflux and finally renal failure with life-threatening consequences (1). Treatment of urinary system dysfunction is primarily aimed at preventing upper urinary tract damage and secondarily at gaining continence and improving quality of life and social interactions (2).
Initial treatment is based on clean intermittent catheterization (CIC) and anticholinergic medications. In those who fail to respond to medical treatment, surgical procedures might be needed (3).

Electrical stimulation has been used for the treatment of urinary incontinence in adults for several decades and recently in children $(4,5)$.

Most authors believe that nonimplanted electrical stimulation induces action potential in the afferent fibers of pudendal nerve leading to efferent outflow causing contraction of the striated pelvic floor musculature. In addition, inappropriate 
detrusor activity might be inhibited by this modality (6).

Functional electrical stimulation (FES) is the application of electrical current to the excitable tissue to improve function that is lost in neurologically impaired individuals. It is a useful noninvasive therapeutic option that is used as a conservative treatment with positive results in bladder overactivity (7).

Many patients with urge, stress and mixed urinary incontinence have been treated with FES using anal or vaginal electrodes which resulted in inhibitory reflexes against spontaneous detrusor contraction (8).

To our knowledge, there has been no reported study evaluating the effects of transcutaneous functional electrical stimulation on urinary incontinence and urodynamic study (UDS) parameters in MMC children. This therapeutic option was used in form of a pilot study to improve urinary incontinence symptoms in MMC patients.

\section{MATERIALS AND METHODS}

Between August 2007 and March 2009, 12 children ( 6 boys and 6 girls) with neuropathic urinary incontinence secondary to MMC who were referred to our clinic at Children's Hospital Medical Center, Tehran University of Medical Sciences, were enrolled in the present study. This study was approved by the local Ethics Committee and written informed consent was obtained from all children's caregivers. Inclusion criteria were defined as children with MMC, aged more than 3 years and moderate to severe urinary incontinence with unsatisfactory response to conventional treatment (requiring CIC every 3 to 4 hours and use of pads). Urological evaluation consisted of renal ultrasonography, urinalysis and UDS. Urodynamic parameters including mean bladder capacity (MBC) and detrusor leak point pressure (DLPP), were recorded according to recommendations by International Children's Continence Society (ICCS) (9).

Daily incontinence score, the episodes of nighttime wetting (the number of nights that the child involuntarily micturates during sleep in a one-week period) and frequency of pad changing (the number of leakage episodes between two con- secutive CICs) were recorded in a voiding diary by parents. The daily incontinence score was recorded on a $0-3$ scale, as described by Schurch et al. score 0 , completely dry; 1 , wet once a day, usually at night (mild); 2 , wet for $<50 \%$ of the time between CIC (moderate); and 3, wet for $>50 \%$ of the time between CIC (severe) (10). A decrement of 2 or more degrees in the daytime incontinence score was considered as "improvement".

UDS (F.M. Wiest Medizintechnik GmbH, Unterhaching, Germany) was performed according to recommendations by the ICCS in all patients in a supine position (9). The intravesical and abdominal pressures were measured simultaneously with a double lumen catheter and with a rectal balloon catheter. EMG was recorded with superficial electrodes in the perineal area. Special attention was given to detrusor leak point pressure (DLPP) and maximal bladder capacity. The same protocol was used for the UDS performed three months after FES courses. Anticholinergic medications were discontinued at least seven days prior to both UDS sessions. Subjective success was assessed by voiding diary and was compared to objective measurements of UDS.

Following the pretreatment UDS, conventional treatment (anticholinergic and CIC) was continued and children received 15 courses of transcutaneous FES for 15 minutes in each session, 3 times per week.

The same electrical stimulation device (model 755X, one-channel NOVIN, Isfahan, Iran) was used for all the patients. Stimulation was delivered with an adjustable power setting. Two rectangular selfadhesive $(2.5 \times 2.5 \mathrm{~cm})$ electrodes were used. Positive electrode was placed on the skin above the pubic symphysis, and the negative one was placed on the skin under urethra.

In all treatment sessions, we used $40 \mathrm{~Hz}$ frequency (to cover both the irritative and obstructive symptoms and stimulate striated muscle fibers and urethral sphincter in pelvic floor), duration of $250 \mu \mathrm{s}$ with hold and rest time of 2 seconds. The intensity was increased until the child experienced a strong but comfortable level of muscle contractions. Maximum current intensity was below the pain threshold and well tolerated by the children. In younger children, an intensity setting of $<30 \mathrm{~mA}$ was used. Median current intensity in others was 40 (range: 20-65) mA. 
Children were followed for more than 3 months. All patients underwent UDS three months after the 15 courses of FES.

Statistical analysis was performed by SPSS 16.0 software (SPSS Inc., Chicago, IL). The Wilcoxon-Signed rank test was executed for non parametric statistical comparisons before and after treatment. $\mathrm{P}$ value of less than 0.05 was considered statistically significant.

\section{RESULTS}

Twelve MMC children including six girls and six boys were enrolled in the present study. Median age of the patients was 5.04 (range: 3-11 years). Demographic data of children are described in Table1.

Two of twelve patients became completely dry between two consecutive CICs. Daily incontinence score was improved from 3 to 1 in five children. Three children remained unchanged for their daily incontinence score. Of those three children who failed to respond to electrical stimulation, two were totally incontinent (Daily incontinence score: 3 ) initially before the treatment.

Details of voiding characteristics and UDS parameters before and after FES therapy are summarized in Table-2. Overall, median daily incontinence score was improved from 3 (range: $2-3$ ) to 1 (range: $0-3)(P=0.006)$. Median frequency of pad changing was significantly decreased from 6 (range: $2-8)$ to 2 (range: $0-7)$ times/day $(\mathrm{P}=0.004)$. Median episodes of night wetting was 3 (range: 2-7) night/week before the electrical stimulation, which improved to 2 (range: 1-7) night/week after the treatment $(\mathrm{P}=0.06)$.

Both of two UDS parameters were significantly improved after treatment. Median DLPP was significantly increased from 38.5 (range: 12-50) $\mathrm{cm}_{2} \mathrm{O}$ to 59.5 (range: $\left.18-83\right) \mathrm{cm}_{2} \mathrm{O}(\mathrm{P}=0.003)$. $\mathrm{MBC}$ was significantly increased from median value of 155 (range: 60-250) $\mathrm{mL}$ to 200 (range: $110-300) \mathrm{mL}(\mathrm{P}=0.007)$. No significant adverse effect was reported by the children and their parents after treatment.

Table 1 - Clinical features and underlying pathology of children with myelomeningocele.

\begin{tabular}{|c|c|c|c|c|c|}
\hline Patient & Age (years) & Gender & Level of MMC $\dagger$ & Concurrent Disability & Movement Weakness \\
\hline 1 & 5 & M & Sacral & Club foot & Distal \\
\hline 2 & 4 & $\mathrm{~F}$ & Lower lumbar & Club foot & Distal \\
\hline 3 & 10 & M & Sacral & None & Normal \\
\hline 4 & 4 & $\mathrm{~F}$ & Lower lumbar & $\begin{array}{l}\text { Club foot } \\
\text { DDH } t\end{array}$ & Distal \\
\hline 5 & 4 & $\mathrm{~F}$ & Sacral & None & Normal \\
\hline 6 & 11 & M & Lower lumbar & None & Distal \\
\hline 7 & 3.5 & $\mathrm{~F}$ & Upper lumbar & $\mathrm{DDH}$ & Paraplegic \\
\hline 8 & 3.5 & M & Lower lumbar & Club foot & Distal \\
\hline 9 & 3 & $\mathrm{~F}$ & Upper lumbar & Hydrocephalus & Paraplegic \\
\hline 10 & 3 & M & Lower lumbar & $\begin{array}{l}\text { Club foot } \\
\text { DDH }\end{array}$ & Distal \\
\hline 11 & 6 & $\mathrm{~F}$ & Upper lumbar & $\begin{array}{l}\text { Hydrocephalus } \\
\text { DDH }\end{array}$ & Paraplegic \\
\hline 12 & 3.5 & M & Lower lumbar & Club foot & Distal \\
\hline
\end{tabular}

$M M C=$ myelomeningocele $; D D H=$ developmental dislocation of hip. 
Electrical Stimulation in Urinary Incontinence

Table 2 - Voiding and urodynamic parameters of children before and after FES therapy.

\begin{tabular}{|c|c|c|c|c|c|c|c|c|c|c|}
\hline \multirow[t]{2}{*}{ Patient } & \multicolumn{2}{|c|}{$\begin{array}{c}\text { Daily } \\
\text { Incontinence Score }\end{array}$} & \multicolumn{2}{|c|}{$\begin{array}{c}\text { Frequency of } \\
\text { Pad Changing } \\
\text { (times/day) }\end{array}$} & \multicolumn{2}{|c|}{$\begin{array}{c}\text { Enuresis } \\
\text { (night/weak) }\end{array}$} & \multicolumn{2}{|c|}{$\begin{array}{c}\text { DLPP } \\
\left(\mathrm{cm} \mathrm{H}_{2} \mathrm{O}\right)\end{array}$} & \multicolumn{2}{|c|}{$\begin{array}{r}\text { MBC } \\
(\mathrm{mL})\end{array}$} \\
\hline & Before & After & Before & After & Before & After & Before & After & Before & After \\
\hline 1 & 3 & 0 & 7 & 0 & 3 & 2 & 40 & 74 & 250 & 300 \\
\hline 2 & 3 & 1 & 7 & 2 & 4 & 4 & 40 & 60 & 250 & 260 \\
\hline 3 & 3 & 3 & 7 & 7 & 7 & 7 & 44 & 48 & 160 & 170 \\
\hline 4 & 2 & 0 & 6 & 2 & 3 & 1 & 12 & 18 & 190 & 200 \\
\hline 5 & 2 & 1 & 2 & 1 & 2 & 2 & 16 & 38 & 180 & 200 \\
\hline 6 & 3 & 2 & 8 & 5 & 2 & 2 & 35 & 48 & 100 & 200 \\
\hline 7 & 3 & 1 & 4 & 1 & 3 & 2 & 35 & 83 & 150 & 250 \\
\hline 8 & 3 & 2 & 6 & 2 & 2 & 2 & 40 & 59 & 60 & 130 \\
\hline 9 & 2 & 2 & 5 & 2 & 7 & 7 & 50 & 62 & 130 & 190 \\
\hline 10 & 3 & 1 & 6 & 3 & 3 & 1 & 39 & 60 & 110 & 110 \\
\hline 11 & 3 & 1 & 5 & 2 & 3 & 3 & 38 & 75 & 200 & 200 \\
\hline 12 & 3 & 3 & 4 & 4 & 2 & 2 & 30 & 30 & 110 & 110 \\
\hline
\end{tabular}

$D L P P=$ detrusor leak point pressure; FES = functional electrical stimulation; $M B C=$ maximal bladder capacity.

\section{COMMENTS}

Myelomeningocele repair is still challenging in the literature. Unfavorable effects of prenatal intervention on postnatal bladder function include poor compliance, poor detrusor contractility, detrusor-sphincter dyssynergia, hydronephrosis and vesicoureteral reflux. This may highlight the existence of bladder developmental defects in these children (11).

In patients with $\mathrm{MMC}$, hyperactivity or inactivity of either detrusor or external urethral sphincter leads to bladder-sphincter dysfunction and ultimately urinary incontinence and poor quality of life. In most of the children, urinary continence can be gained with bladder emptying by CIC and anticholinergic medication.

Continent catheterizable urinary diversion is applied in patients who do not respond to anticholinergic medications. However, it may be complicated by urinary tract infection, distal dehiscence of conduit, stomal stenosis, and urinary stomal leakage (12).
Mini-invasive collagen sling has also been used as a safe and easy method with promising immediate results in patients with neurogenic urinary incontinence. However, a one-year follow-up study failed to demonstrate beneficial long term outcome (13).

Electrical stimulation, as a clinical non-invasive treatment option to manage the urinary incontinence symptoms, was first introduced by Caldwell and colleagues (14).

Numerous electrical stimulation methods have been reported to be effective for the treatment of lower urinary tract dysfunction (15).

There are many evidences that electrical stimulation can lead to activation of detrusor inhibitory reflex as well as striated urethral muscles contraction (4). This kind of treatment can cause hypertrophy of muscle fibers, possibly by the recruitment of motor units with faster conduction and alter the expression of myosin isoforms, favoring a conversion to type 1 muscle fibers (4). An effect of FES at the peripheral level can be modulation of neurotransmitters such as 
cholinergic and $\beta$-adrenergic system (16). In a study by Ishigooka et al., reduction in norepinephrine content of the rabbit urinary bladder by a combination of yohimbine and electrical stimulation of pelvic floor musculature has been reported. These authors have suggested the reflexive activation of hypogastric nerves following pelvic floor stimulation (17). This finding can describe the effect of FES therapy in patients with bladder overactivity.

Therapeutic effects of FES may be achieved through normalization and balance between cholinergic and beta-adrenergic neurotransmitters (8). The prolonged intravaginal FES restores the normal reflex pattern of detrusor function through reorganization of the neural system innervating the bladder (18).

Results of our present pilot study revealed that transcutaneous FES of striated urethral sphincter decreased daily incontinence score, number of enuresis, and frequency of pad changing in $75 \%$ of MMC patients. In addition, significant improvement obtained in the UDS parameters (DLPP, MBC) three months after the treatment. We used this form of stimulation to strengthen the striated urethral muscles and to normalize voiding pattern with activation of afferent fibers of pudendal nerve in the perineal region.

We have yielded improvement in urinary symptoms of children with MMC applying FES in the present study, which was similar to the results of our previous study in MMC children. In our previous study, we used interferential electrical current to decrease urinary incontinence symptoms in MMC children with bladder overactivity: in which $78 \%$ of patients gained continence immediately after treatment and $60 \%$ of patients remained continent for 6 months or more (15).

To our knowledge, there is no report on the efficacy of FES on urinary symptoms in MMC children. There are several studies investigating therapeutic effects of FES on urinary incontinence among adult female subjects.

Primuse and Kramer reported effects of FES treatment using intravaginal or intra-anal electrodes in 75 patients with complaints of urgency and/or urge incontinence (30 multiple sclerosis and 45 idiopathic patients). In these patients, 59\% experienced significant urodynamic and subjective improvement after the treatment and additional $40 \%$ of the patients had only subjective improvement of urinary symptoms. Therapeutic effects of electrical stimulation remained for at least 2 years in $64 \%$ of patients with idiopathic urinary incontinence while early symptom relapse occurred 2 months after the treatment in multiple sclerosis group (8).

In a study by Hung et al., the effect of FESbiofeedback and pelvic floor muscle exercise on symptoms of women with genuine stress urinary incontinence has been investigated. They have reported that the level of discomfort in daily life, social activity, physical activity, and personal relations due to urinary symptoms had significantly improved especially in the FES-biofeedback group (19).

In a study by Kralj et al., effect of FES on female urinary incontinence has been evaluated. They have reported $50.5 \%$ cure, $23.4 \%$ improvement of symptoms, and $26.1 \%$ treatment failure three months after the treatment (20).

Eskiyurt et al., have compared the effectiveness of two therapeutic method including functional magnetic stimulation (FMS) and functional electrical stimulation (FES) in 22 women with mixed urinary incontinence. Urinary diaries and micturition frequency was more cured and improved in those treated by FES than FMS. However, there was no significant reduction of nocturnal voiding frequency in both groups (21).

There are several limitations in our present study including small sample size, lack of sham-controlled group, and short duration of follow-up. It will be necessary to design future studies to investigate the role of FES therapy in children with myelomeningocele and compare its effect in a sham-controlled design.

\section{CONCLUSIONS}

This type of electrical stimulation is an effective and inexpensive therapeutic method for urinary incontinence in children affected by myelomeningocele with no considerable adverse effects and can be used at home. Applying transcutaneous electrodes makes this type of electrical stimulation a less invasive therapeutic method than anal or vaginal electrode and seems to be better tolerated by children. 


\section{CONFLICT OF INTEREST}

\author{
None declared.
}

\section{REFERENCES}

1. Wu HY, Baskin LS, Kogan BA: Neurogenic bladder dysfunction due to myelomeningocele: neonatal versus childhood treatment. J Urol. 1997; 157: 2295-7.

2. Nijman RJ: Neurogenic and non-neurogenic bladder dysfunction. Curr Opin Urol. 2001; 11: 577-83.

3. Kajbafzadeh AM, Chubak N: Simultaneous Malone antegrade continent enema and Mitrofanoff principle using the divided appendix: report of a new technique for prevention of stoma complications. J Urol. 2001; 165: 2404-9.

4. Fehrling M, Fall M, Peeker R: Maximal functional electrical stimulation as a single treatment: is it costeffective? Scand J Urol Nephrol. 2007; 41: 132-7.

5. Malm-Buatsi E, Nepple KG, Boyt MA, Austin JC, Cooper CS: Efficacy of transcutaneous electrical nerve stimulation in children with overactive bladder refractory to pharmacotherapy. Urology. 2007; 70: 980-3.

6. Brubaker L: Electrical stimulation in overactive bladder. Urology. 2000; 55(5A Suppl): 17-23; discussion 31-2.

7. Bower WF, Yeung CK: A review of non-invasive electro neuromodulation as an intervention for nonneurogenic bladder dysfunction in children. Neurourol Urodyn. 2004; 23: 63-7.

8. Primus G, Kramer G: Maximal external electrical stimulation for treatment of neurogenic or non-neurogenic urgency and/or urge incontinence. Neurourol Urodyn. 1996; 15: 187-94.

9. Nevéus T, von Gontard A, Hoebeke P, Hjälmås K, Bauer S, Bower W, et al.: The standardization of terminology of lower urinary tract function in children and adolescents: report from the Standardisation Committee of the International Children's Continence Society. J Urol. 2006; 176: 314-24.

10. Schurch B, Stöhrer M, Kramer G, Schmid DM, Gaul G, Hauri D: Botulinum-A toxin for treating detrusor hyperreflexia in spinal cord injured patients: a new alternative to anticholinergic drugs? Preliminary results. J Urol. 2000; 164: 692-7.

11. Swana HS, Sutherland RS, Baskin L: Prenatal intervention for urinary obstruction and myelomeningocele. Int Braz J Urol. 2004; 30: 40-8.

12. Barbosa LL, Liguori R, Ottoni SL, Barroso U Jr, Ortiz $\mathrm{V}$, Macedo A Jr: Is continent urinary diversion feasible in children under five years of age? Int Braz J Urol. 2009; 35: 459-66.

13. Taskinen S, Fagerholm R, Rintala R: Mini-invasive collagen sling in the treatment of urinary incontinence due to sphincteric incompetence. Int Braz J Urol. 2007; 33: 395-400; discussion 400-6.

14. Caldwell KP: The electrical control of sphincter incompetence. Lancet. 1963; 2: 174-5.

15. Kajbafzadeh AM, Sharifi-Rad L, Baradaran N, Nejat F: Effect of pelvic floor interferential electrostimulation on urodynamic parameters and incontinency of children with myelomeningocele and detrusor overactivity. Urology. 2009; 74: 324-9.

16. Okada N, Igawa Y, Ogawa A, Nishizawa O: Transcutaneous electrical stimulation of thigh muscles in the treatment of detrusor overactivity. Br J Urol. 1998; 81: 560-4.

17. Ishigooka M, Hashimoto T, Sasagawa I, Nakada T: Reduction in norepinephrine content of the rabbit urinary bladder by alpha-2 adrenergic antagonist after electrical pelvic floor stimulation. J Urol. 1994; 151: 774-5.

18. Fall M, Lindström S: Electrical stimulation. A physiologic approach to the treatment of urinary incontinence. Urol Clin North Am. 1991; 18: 393-407.

19. Sung MS, Hong JY, Choi YH, Baik SH, Yoon H: FESbiofeedback versus intensive pelvic floor muscle exercise for the prevention and treatment of genuine stress incontinence. J Korean Med Sci. 2000; 15: 303-8.

20. Kralj B: Conservative treatment of female stress urinary incontinence with functional electrical stimulation. Eur J Obstet Gynecol Reprod Biol. 1999; 85: 53-6.

21. Bölükbas N, Vural M, Karan A, Yalçin O, Eskiyurt N: Effectiveness of functional magnetic versus electrical stimulation in women with urinary incontinence. Eura Medicophys. 2005; 41: 297-301.

Accepted after revision: February 27, 2010

\section{Correspondence address:}

Dr. Abdol-Mohammad Kajbafzadeh

No. 36, 2nd Floor, 7th Street

Saadat-Abad, Ave.

Tehran, 1998714616, Iran

Fax: + 9821 2206-9451

E-mail:kajbafzd@sina.tums.ac.ir 


\section{EDITORIAL COMMENT}

Children with lower urinary tract congenital anomalies such as bladder exstrophy, myelomeningocele, or posterior urethral valves, can develop complex clinical pictures consisting in high-pressure/low flow and hypertonic low compliant bladders (1). These patients often may need surgical treatment (i.e. cystoplasty) as they often develop resistance to drug treatment.

In children with myelomeningocele, the main aim of treatment is to improve the functionality of diseased bladders by decreasing the intravesical pressures, improving bladder compliance, urinary and fecal continence and patient's quality of life. Patients with a poorly compliant bladder may incur renal damage over time and thus an early effective and conservative management of bladder dysfunction is welcome. Surgical treatment may be effective, but side effects are not negligible: bladder augmentation is usually done with gastrointestinal segments, which can lead to metabolic abnormalities such as acidosis or alkalosis, depending on the segment used, an increased rate of calculi formation, increased mucus production, and enhanced risk of malignant disease $(2,3)$.

Kajbafzadeh and colleagues in this issue of International Brazil Journal of Urology investigated the efficacy of transcutaneous functional electrical stimulation (FES) in a small group of children with myelomeningocele and lower urinary tract dysfunc- tion. Over 12 patients, 9 children reported an improvement on urinary incontinence score, although three children had no improvement. It is interesting to note that the detrusor leak point pressure was significantly improved as well as the maximum bladder capacity. Authors concluded that FES therapy might have positive effects on improvement of voiding symptoms of children with neurogenic urinary incontinence in terms of daily incontinence score and urodynamic parameters.

Every conservative strategy to improve lower urinary dysfunction of children with neurogenic bladder is welcome, but long-term multiparametric (objective and subjective) follow-up remains the challenge for next generation of pediatric and adult urologists.

\section{REFERENCES}

1. Snodgrass WT, Adams R: Initial urologic management of myelomeningocele. Urol Clin North Am. 2004; 31 : 427-34.

2. McDougal WS: Metabolic complications of urinary intestinal diversion. J Urol. 1992; 147: 1199-208.

3. Soergel TM, Cain MP, Misseri R, Gardner TA, Koch MO, Rink RC: Transitional cell carcinoma of the bladder following augmentation cystoplasty for the neuropathic bladder. J Urol. 2004; 172: 1649-51; discussion 1651-2.

Dr. Massimo Lazzeri

Department of Urology

San Raffaele Hospital

Vita-Salute University San Raffaele Turro Milan, Italy 